\title{
Why ecological footprint calculators should move beyond in- formation provision - An empirical study of the relationship between environmental knowledge and ecological footprint
}

\author{
Anne L. Kok ${ }^{1}$ and Wolmet Barendregt ${ }^{1, *}$ \\ 1 Human-Technology Interaction Group, Department of Industrial Engineering and Innovation Sciences, \\ Eindhoven University of Technology, PO Box 513, 5600 MB, Eindhoven, The Netherlands; annelin- \\ dakok@gmail.com \\ * Correspondence: w.barendregt@tue.nl
}

\begin{abstract}
Ecological footprint calculators are digital tools that help individuals calculate their environmental or climate impact, with the aim of stimulating pro-environmental behaviour change. These footprint calculators typically take an information-provision approach, but this strategy assumes that increased levels of knowledge result in increased levels of pro-environmental behaviour (i.e., a reduced footprint). This is not a given - existing literature on the relationship between environmental knowledge and pro-environmental behaviour is inconclusive, and this relationship may be different from that of environmental knowledge and ecological footprint. As such, we investigated the relationship between environmental knowledge and ecological footprint as estimated by a footprint calculator. 448 Dutch participants completed an online survey, including an ecological footprint calculator. We found no evidence for a relationship between environmental knowledge and ecological footprint calculator outcome. Rather, an exploratory analysis of our data showed that environmental values were more important predictors of ecological footprint. The finding that increased levels of knowledge are not related to a reduced ecological footprint suggests that calculators would do well to move beyond information provision, and employ additional behaviour change strategies. Based on our exploratory analysis, we provide several concrete examples of potential strategies.
\end{abstract}

Keywords: ecological footprint calculator; ecological footprint; ecological behaviour; pro-environmental behaviour; environmental knowledge; environmental education; environmental values; carbon footprint calculator; carbon footprint

\section{Introduction}

Around the world, human actions are causing environmental changes [1]. This is not without risk. Exceeding our planet's boundaries could have disastrous consequences [2], such as an increased rate of sea level rise, an increased risk of great floods, and a larger number of - potentially lethal - heat waves, due to crossing the climate boundary [3-5]. Other boundaries concern ozone depletion, biodiversity loss, and water and land use [2]. Consumption at individual and household level is an important contributor to the crossing of these planetary boundaries. For example, more than 60 percent of global greenhouse gas emissions is caused by households [6]. To persuade people to reduce their environmental impact, top-down policies are being supplemented with bottom-up tools aimed at consumers, such as ecological footprint calculators (e.g., [7,8]).

Ecological footprint calculators calculate their users' ecological footprint based on information about their lifestyle (e.g., housing, expenses, travel habits, diet). This ecological footprint is a measure of ecological impact, which includes $\mathrm{CO}_{2}$ emissions as well as water and land use [9], all of which are highly relevant in terms of planetary boundaries [2]. A well-known variation of the ecological footprint calculator is the carbon foot- 
print calculator (or 'carbon calculator' for short) - a tool which focuses only on the calculation of $\mathrm{CO}_{2}$ emissions and climate change rather than other environmental issues.

Results of ecological footprint calculators are typically presented to users in terms of global hectares required to facilitate the user's lifestyle, and/or in terms of the number of 'Earths' that would be needed if everyone on the planet had the same consumption pattern as the user. In addition, calculators usually offer advice about how users could reduce their carbon footprint, and often show how the user's footprint compares to that of others $[7,8]$. The aim is to raise environmental awareness, and ultimately, to persuade users to change their behaviour and reduce their environmental impact.

These calculators tend to take an information-provision approach, providing users with insights about the causes of climate change, the meaning and size of their footprint, and ways to reduce this footprint. However, the question is whether increasing users' environmental knowledge is indeed an effective method to achieve behaviour change. Many studies have investigated the relationship between knowledge and pro-environmental behaviour, but results are inconclusive (e.g., [10-12]). Importantly, differences in pro-environmental behaviour may not translate to differences in ecological footprint $[13,14]$. The aim of this study was to shed a light on the relationship between environmental knowledge and ecological footprint calculator outcome, to determine whether calculators' information-provision approach is justified. We did not find evidence for this relationship, and as such, we conclude that calculators would do well to move beyond information provision, and employ additional behaviour change strategies.

\subsection{Effects of ecological footprint calculators on behaviour}

While technology can be used to influence human behaviour and thinking [15] and to promote sustainable behaviour [16], little is known about the behavioural effects of ecological footprint calculators. Calculator users have reported that the tools increased their knowledge and awareness about their climate impact and ways to reduce it [17-21], and also increased their motivation to reduce their footprint [22].

Unfortunately, evidence about the effect of footprint calculators on actual behaviour is limited and inconclusive [23]. A small number of studies have found that completing an ecological footprint calculator and receiving advice about how to reduce one's footprint does not result in changes in behavioural intentions [24] or changes in behaviour, even when the advice is personalised [17]. This is in line with literature from the home energy domain showing that while eco-feedback can help increase knowledge and awareness, this does not necessarily result in behavioural changes [25-27].

However, other studies have shown more promising results. For example, some visitors of an online carbon footprint calculator website reported (after two weeks) that they had made changes to heating, electricity and dietary behaviours [20]. Similarly, participants in an ecological footprinting study reported that two months after seeing their results, they had made changes in their consumption patterns [28]. Students who completed a carbon footprint calculator in combination with focus group discussions also reported to have made some small changes to their lifestyle as a result [18], and students who used a carbon footprint management system (including various persuasive techniques) on a weekly basis showed reduced carbon emissions after four and six weeks [29]. Finally, a long-term study where a bi-monthly carbon calculator was used as part of a local climate initiative found that the initiative had reduced participants' $\mathrm{CO}_{2}$ emissions [19].

\subsection{Criticism of the information-provision approach}

The above findings suggest that ecological footprint calculators may be able to reach their goal of increasing pro-environmental behaviour - but many of the studies that have found an effect involved methods other than information provision, such as focus groups and persuasive techniques. Indeed, scholars have suggested that the information-provision approach taken by many calculators may not be the best way to 
achieve behaviour change $[8,20,21]$, because many factors other than knowledge play a role in pro-environmental behaviour [30,31].

These other factors are both attitudinal and contextual. For instance, the well-known Value-Belief-Norm (VBN) theory of pro-environmental behaviour [32] posits that individuals' environmental values are at the root of their pro-environmental behaviour. Environmental values include biospheric values (concern for the environment), altruistic values (concern for others), egoistic values (concern for the self), and hedonic values (related to living a 'good life'). Individuals with strong biospheric and altruistic values tend to show more pro-environmental atitudes and behaviours; the opposite is true for individuals with strong egoistic and hedonic values [33-35].

On the contextual side, income is one of the most important, if not the most important, determinant of pro-environmental behaviour. Those with higher incomes are less likely to adopt pro-environmental behaviours [36,37]. Accordingly, higher incomes are associated with higher domestic electricity consumption [38], higher estimated energy use [37,39], and higher carbon emissions [14,40-44].

It thus may be the case that the criticism of calculators' information-provision approach is warranted, but to determine this, a closer investigation of the relationship between knowledge and ecological footprint is required. Ideally, one would measure longitudinally whether an ecological footprint calculator increases knowledge, and whether that translates into relevant behaviour change - i.e., into a reduced ecological footprint. However, for the purposes of this time-constrained study, we focus on the second part of the chain, and pose the following research question.

$R Q$. What is the relationship between individuals' level of environmental knowledge and their ecological footprint as estimated by a footprint calculator?

\subsection{Environmental knowledge and ecological footprint}

Knowledge is generally viewed as a necessary, but not a sufficient condition for pro-environmental behaviour [30,31,45]. In other words, "although knowledge does not always have the intended effect on a target behaviour itself, it may at least fuel other mechanisms that facilitate behaviour change" [46] (p. 1598). Possibly as a result of this, evidence about the relationship between environmental knowledge and pro-environmental behaviour is highly varied. Many studies have found a direct positive relationship [11,47-51], but others have only found indirect effects. Most notably, meta-analyses [52,53] support an indirect positive relationship of environmental knowledge and pro-environmental behaviour, mediated by behavioural intentions, normative variables and guilt. Several studies have found environmental attitudes or emotions to be a mediating factor (e.g., $[10,54]$, see also $[55,56])$, but this mediation does not always occur [47]. Finally, some studies have found no evidence at all for a (direct) relationship between knowledge and pro-environmental behaviour [12,57].

Importantly, the relationship between knowledge and pro-environmental behaviour may not be the same as the relationship between knowledge and ecological footprint. This is because instruments typically used to measure pro-environmental behaviour often fail to reflect actual ecological impact. To illustrate, a study by Csutora [13] found that differences in the number of pro-environmental behaviours people claimed to perform did not translate to any differences in their ecological footprint. Similarly, Huddart Kennedy et al. [14] did not find a relationship between people's reported pro-environmental behaviour and their carbon emissions.

To our knowledge, only one study has tested the relationship of environmental knowledge with carbon footprint calculator outcome [58], and did not find support for this relationship. However, this study used a sample of high school students (who do not tend to have much control over their carbon footprint, as they live with their parents), a knowledge scale with poor internal consistency, and only analysed the difference between three knowledge 'levels' rather than considering knowledge as a continuous var- 
iable. As such, more research is needed. We aim to fill this gap by using a more representative sample and a reliable and continuous knowledge measure.

Most of the empirical findings listed above support the existence of a (direct or indirect) positive relationship between knowledge and pro-environmental behaviour. Assuming that this relationship translates to a relationship with ecological footprint, we pose the following hypothesis.

H1. Individuals with higher levels of environmental knowledge have smaller ecological footprint calculator outcomes (i.e., smaller estimated footprints).

\subsection{Types of environmental knowledge}

It should be kept in mind that environmental knowledge is not a concept that is easily defined. Scholars have distinguished between different types of environmental knowledge, most importantly between declarative or system knowledge on the one hand (knowledge about environmental systems and the processes within them) and procedural or action knowledge (action-related knowledge about possible pro-environmental behaviours) on the other hand $[11,45,46,59,60]$. Ecological footprint calculators may try to improve both of those knowledge types. For example, they may attempt to convey system knowledge related to ecological footprints and climate change. They may also attempt to convey action knowledge by providing advice on how to reduce one's footprint. ${ }^{1}$ While Frick et al. [46] found an empirical distinction between these two knowledge types, Geiger et al. [50] failed to find support for such an empirical distinction, and in a study by Díaz-Siefer et al. [11] the relationship with pro-environmental behaviour was very similar for human-environment system knowledge and action knowledge. This suggests that while both types of knowledge may be relevant to ecological footprint calculators, there is insufficient evidence to assume that their relationship to pro-environmental behaviour would be different.

\section{Materials and Methods}

To test our hypotheses, we performed a cross-sectional study. In the spring of 2020, 448 Dutch participants (233 women, 215 men, $M_{\text {age }}=39.8$ years, $S D_{\text {age }}=15.1$ years, age range: $18-83$ years) took part in this study via an online survey. Participants were recruited through PanelClix (a Dutch research panel; https://panelclix.nl) and through social media.

What follows is an overview of the measures used in this study. A full list of all survey questions, in the order in which they appeared in the survey, is presented in the Supplementary Materials. Based on several measured variables, suspected fraudulent responses were identified and dropped from the dataset prior to analysis (final $N=448$ ). Details about exclusion criteria are also presented in the Supplementary Materials.

Environmental knowledge. Because both system and action knowledge may be targeted by ecological footprint calculators and because there is insufficient evidence to suggest they are empirically distinguishable, we measured environmental knowledge as a general concept (including questions related to both system knowledge and action knowledge, but without explicit subscales). For this purpose, the scale developed by Carmi et al. [10] (Cronbach's $\alpha=0.72$ ) was used. This scale consists of 18 items (factual statements) that participants have to judge as being either true or false. An answer option 'I don't know' was also included, and participants were instructed to choose this option if they did not know the answer. The scale by Carmi et al. [10] was originally developed in Israel. It was translated to Dutch for this study and adapted to The Netherlands. For the complete list of items, see the survey overview in the Supplementary Materials. From the

\footnotetext{
${ }^{1}$ For example, the web-based calculator by WWF-Netherlands (https://voetafdruktest.wwf.nl/) offers information about ecological footprints (system knowledge) as well as tips to reduce your footprint (action knowledge). The Belgian app-based calculator For Good (https://www.forgood.eco/) regularly notifies users of environmentally relevant news items (both system and action knowledge).
} 
18 environmental knowledge items, a knowledge score was created by counting each correct answer as 1 and each wrong or 'I don't know' answer as 0 . Environmental knowledge was measured prior to directing participants to the footprint calculator.

Ecological footprint calculator outcome was measured using an external ecological footprint calculator, and quantified as the estimated number of global hectares required on a yearly basis to facilitate a participant's reported consumption pattern. The calculator used in this study (https://brabantsevoetafdruk.nl/) was selected because (a) it is in Dutch; (b) it allows users to specify whether they use an electric vehicle, which is rare in footprint calculators [61]; and (c) it does not require users to enter their exact energy consumption (e.g. in $\mathrm{kWh}$ electricity or $\mathrm{m}^{3}$ gas), which increases usability, an important characteristic of footprint calculators [8]. The calculator asked 56 multiple choice questions about eight consumption categories: food, holidays, transport, clothing, housing, electricity and heating, paper and waste, and the purchasing of goods (full questions are listed in the Supplementary Materials). Participants copied their footprint calculator outcome in hectares to the survey (both the total global hectares and the hectares per consumption category).

Environmental values and income were included as control variables, because they are important predictors of pro-environmental behaviour, as previously discussed. Environmental values were measured using the Dutch version of the Environmental Portrait Value Questionnaire [E-PVQ; 62]. Each item in the E-PVQ describes a person's values ("It is important to [him/her] to..."). Participants were asked to indicate on a 7-point scale how much the person in the description was similar to themselves $(1=$ not like me at all, 7 = very much like me) $[62,63]$. Scales were created for each of the four value orientations: biospheric (Cronbach's $\alpha=0.90)$, altruistic $(\alpha=0.76)$, hedonic $(\alpha=0.82)$, and egoistic values $(\alpha=0.82)$. To measure income, participants were asked to report their average monthly net household income. Participants were first asked for their income with an open-ended question; if they did not answer this question, response brackets (categories) were presented to decrease item non-response [64]. In total, 85\% of participants answered the open question about income. An additional 9\% answered the bracketed question. Environmental values were measured prior to directing participants to the footprint calculator; income was measured at the end of the survey.

Finally, age, gender, and level of education were included as control variables, because they can be related to environmental attitudes, preferences and behaviours $[30,31,36,37,65,66]$.

\section{Results}

\subsection{Descriptive statistics}

Participants' average knowledge score was 11.22 (range: $0-18, S D=2.84$ ). The distribution of knowledge scores in our sample is presented in Figure 1, which illustrates that there were only few participants who obtained very low knowledge scores: only $5 \%$ of participants answered six or fewer questions correctly, out of a total of 18. For each question, the percentage of participants who answered correctly is shown in the survey overview in the Supplementary Materials.

Participants' average ecological footprint calculator outcome was 5.13 ha $(S D=1.65$ ha). At the time of data collection, the average Dutch ecological footprint listed on the calculator's website was 6.28 ha. (This was updated on the footprint calculator website between the time of data collection and the time of writing. At the time of writing, the average Dutch ecological footprint is listed as 4.89 ha.)

Participants' hedonic values were strongest on the 7-point response scale $(M=6.05$, $S D=0.85)$, followed by altruistic $(M=5.74, S D=0.78)$, biospheric $(M=5.40, S D=1.09)$ and finally egoistic values $(M=3.68, S D=1.16)$. Most participants $(24 \%)$ reported a monthly household income between $€ 2,000$ and $€ 3,000$. Most participants (34\%) reported higher professional education as their highest completed education level, followed by university education (24\%), secondary vocational education (23\%), and secondary education (17\%). 
Compared to the Dutch population of 15-75 years of age [67], the sample for this study was more highly educated.

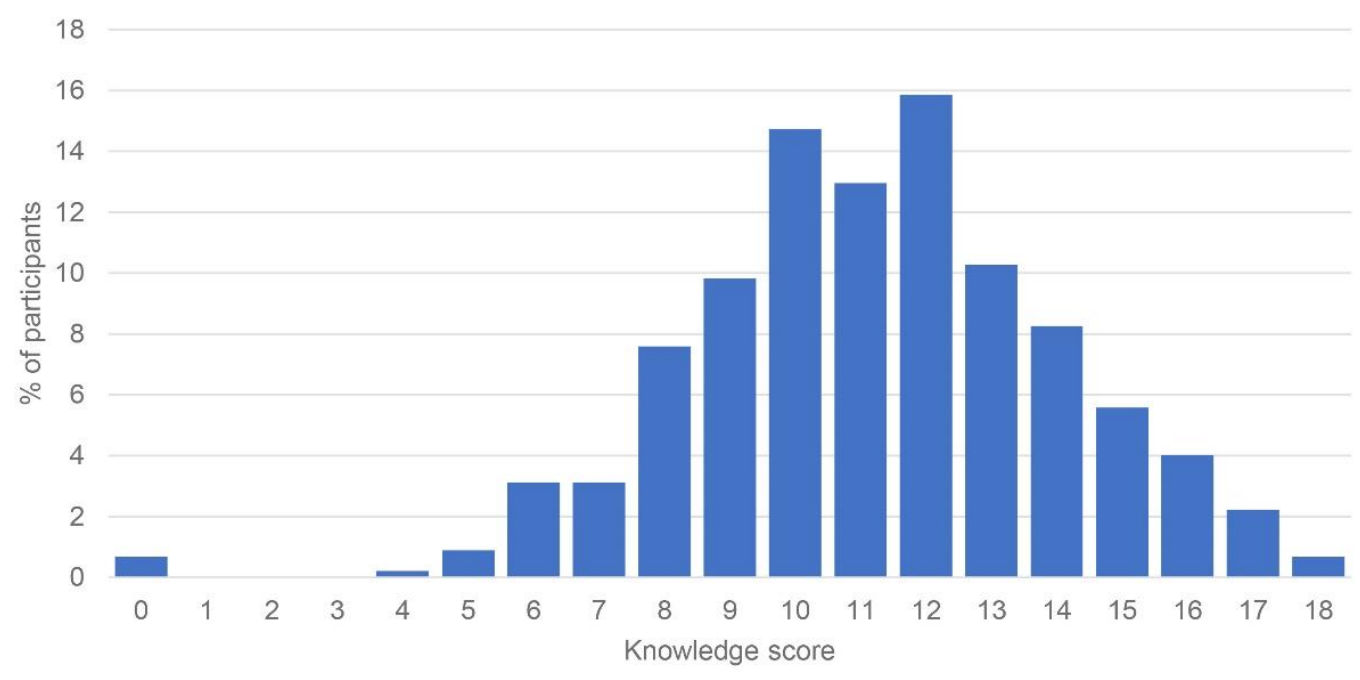

Figure 1. Distribution of environmental knowledge scores.

\subsection{Hypothesis test}

To test the hypothesis that individuals with higher levels of environmental knowledge have smaller ecological footprints, a bivariate correlation was calculated with a one-tailed test of significance. (The Spearman correlation is reported, because there was no bivariate normality between knowledge and footprint calculator outcome as determined by the Doornik-Hansen test [68], $\chi^{2}(4,448)=135.18, p<.001$. This means Pearson's $r$ is not a reliable measure of correlation for our dataset.) Results showed that there was no significant correlation between environmental knowledge and ecological footprint calculator outcome $\left(r_{s}=.01, p=.395\right)$. H1 was thus not supported. As for the individual knowledge items, exploratory correlational analyses showed that only one item (item 9 in the Supplementary Materials) was significantly related to footprint calculator outcome $\left(r_{s}=-.11, p=.026\right)$, while all other items were not.

\subsection{Exploratory regression analysis}

Considering that we found no evidence for a relationship between knowledge and ecological footprint, designers and developers of footprint calculators may do well to focus on other, stronger predictors of ecological footprint. As such, we were interested in the relative impact of our control variables. We ran an exploratory multiple regression analysis (see Table 1) with environmental knowledge and all five control variables as predictors of ecological footprint calculator outcome. Robust standard errors were used to account for heteroscedasticity and non-normal distribution of errors. Dummy variables were created for each education level, with the exception of primary education, because there were too few observations $(n=2)$. This analysis showed biospheric, altruistic, hedonic and egoistic values to be the only significant predictors of ecological footprint calculator outcome, with all predictors together explaining $21 \%$ of variance in calculator outcome.

\section{Discussion}

No significant relationship between environmental knowledge and ecological footprint calculator outcome was found. These results demonstrate that the previous findings by Caparoso et al. [58] also hold for a more representative sample and a more reliable measure of environmental knowledge. Additionally, in our exploratory analysis, only one of the 18 knowledge items was significantly related to footprint calculator outcome, which suggests that like general environmental knowledge, knowledge about more 
specific environmental topics is unlikely to have an important relationship with footprint calculator outcome. These results imply that criticism of ecological footprint calculators' information-provision approach is warranted, and that attempts to increase environmental knowledge alone will not be an effective strategy to achieve the kind of behaviour change that affects environmental impact. As such, ecological footprint calculators should move beyond information provision, and employ other, additional tactics to achieve behaviour change.

Table 1. Summary of Multiple Regression Analysis for Variables Predicting Ecological Footprint Calculator Outcome.

\begin{tabular}{lccc}
\hline Predictor & Estimate & Robust SE & $p$ \\
\hline Female & -0.25 & 0.16 & .119 \\
Age & 0.01 & 0.01 & .053 \\
Secondary ed. & 1.53 & 1.79 & .393 \\
Secondary voc. ed. & -0.39 & 0.84 & .638 \\
Higher prof. ed. & 0.02 & 0.84 & .979 \\
University & 0.20 & 0.84 & .815 \\
Doctorate & -0.16 & 0.84 & .848 \\
Biospheric values & $-0.27^{* *}$ & 0.09 & .002 \\
Altruistic values & $-0.29^{*}$ & 0.13 & .027 \\
Hedonic values & $0.34^{* * *}$ & 0.10 & $<.001$ \\
Egoistic values & $0.34^{* * *}$ & 0.08 & .001 \\
Income ${ }^{1 *}$ & 0.00 & 0.00 & .055 \\
Knowledge & 0.05 & 0.03 & .156 \\
\hline $\mathrm{R}^{2}$ & 0.21 & & $<.001$ \\
F for change in $\mathrm{R}^{2}$ & $6.28^{* * *}$ & & \\
\hline
\end{tabular}

${ }_{1}^{1}$ Categorical responses were included, outliers were excluded (see Supplementary Materials for details).

${ }^{*} \mathrm{p}<.05,{ }^{* *} \mathrm{p}<.01,{ }^{* * *} \mathrm{p}<.001$.

In our exploratory analysis, environmental values were significant predictors of ecological footprint calculator outcome. This finding is in line with past research about the relationship between environmental values and individual pro-environmental behaviours $[33,35]$, and extends recent findings about the relationship between values and carbon footprint [69]. As a result, ecological footprint calculators may consider focusing on values as an alternative to knowledge, a practical implication which will be discussed in more detail in the following section.

\subsection{Alternatives to information provision}

There are many different ways in which ecological footprint calculators could move beyond information provision. At a societal level, it has been suggested that calculators could serve as tools to actively engage users in participatory, community-based environmental action [8,20]. However, for this discussion, we focus on implications for the design and development of ecological footprint calculators as standalone tools.

Considering footprint calculators as behaviour change interventions, they can be improved using various behaviour change techniques [70], such as personalisation and framing. For instance, personalised advice can increase persuasiveness and stimulate behaviour change [71,72], including in the environmental domain [73]. In relation to our findings, personalisation could occur based on users' value orientation. To illustrate, if a footprint calculator wants to advise its users to lower their thermostat, users with strong egoistic values could be shown an egoistic framing ("it will save you money"), while users with strong biospheric values could be shown a biospheric framing ("it will help the 
environment"). Some studies have indeed found that designing interventions or appeals using such 'value-matching' can be effective at increasing behaviour-specific pro-environmental attitudes and intentions [74-79], but others have found only limited effects [80,81] or no effects at all [82,83]. Future research can help clarify how value-matching could increase the persuasiveness of an ecological footprint calculator, and what possible spillover effects may occur (see, e.g., [84]).

Another way in which calculators may utilise framing to increase their persuasiveness may be to step away from a solely environmental framing, by focusing on the so-called 'co-benefits' of pro-environmental behaviour. For example, it has been suggested to include not only resource efficiency, but also factors related to fair trade and employment in developing countries [8], or to emphasise benefits "to public health, nutrition, animal welfare, local economies, community or other incentives that may be associated with less emissions-intensive [behaviours]" [85] (p. 192). In past studies, footprint calculator users have indeed indicated that they performed pro-environmental behaviours mainly for health, economic, and social benefits [86] and suggested that ecological footprinting "should also be sold to people as a way to cut down on household

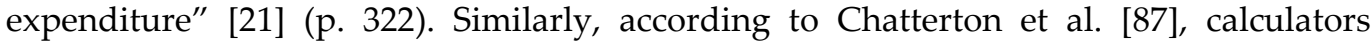
should give an indication of "health and environmental consequences of [behavioural] choices that are likely to be of more immediate relevance to the [...] user in terms of their own self-interest [than climate change]" (p. 48).

Of course, such an indication is still a form of information provision (as is personalised advice). However, it is no longer general, environmental information, but rather information that is personally relevant to the user. This is a more specific type of knowledge than the general environmental knowledge measured in this study. While we believe there is not sufficient empirical evidence to distinguish between environmental system and action knowledge, it may be useful to investigate the effectiveness of more specific knowledge types for behaviour change. For example, would our results have been different if we had measured knowledge about the effects of climate change (e.g., sea level rise) on one's personal life and that of one's children and other loved ones? (In other words, what are the more direct, personally relevant threats when we do not take action?) Or, would our results have been different if we had explicitly measured knowledge about one's ecological footprint and ways to reduce it? Future research could investigate whether these types of knowledge are empirically distinguishable from more general environmental (system or action) knowledge, and whether they are related to ecological footprint.

With this, we emphasise that the results of this study do not imply that all information provision should be forgone. As stated, knowledge may still be a necessary condition for pro-environmental behaviour, playing a facilitating rather than a causal role $[30,31,45,46]$. Furthermore, providing information about a user's footprint is a crucial characteristic of footprint calculators, and users may also appreciate other information, for example about the relative impact of specific (categories of) behaviours [21,88,89]. We merely conclude that providing general information alone is not sufficient to achieve behaviour change, and that this strategy should be complemented by other techniques. We gave several examples related to our findings; more can be found in literature (for an overview, see [70]).

\subsection{Limitations}

In our sample, only very few participants had a low-to-zero knowledge level; in other words, almost all participants had at least some knowledge about the environment. Again considering knowledge as a necessary condition for pro-environmental behaviour $[45,53]$, it may be the case that all of our participants had this necessary 'threshold' knowledge to begin with, meaning the hypothesised effect of knowledge could not be detected. This may be due to self-selection bias: participants who already had some existing environmental knowledge may have been more willing to complete a footprint 
calculator for this study. It also matches with the fact that our sample was relatively highly educated. Future research could investigate whether results are different for samples with lower knowledge levels.

A second limitation of this study is that the footprint calculator which participants completed was developed by an external party. We did not have access to the methodology the calculator used to estimate users' footprint - we only know the 56 questions it consisted of and believe that these questions should have generated sufficient input data to make a reasonably accurate estimate. Correlational analyses such as the one used for our hypothesis test consider differences between participants rather than absolute values, so possible methodological issues of the calculator should not have affected results to a great extent. Still, studies show that similar input parameters in different calculators can lead to vastly different results $[90,91]$. Therefore, results may have been different if a different calculator had been used.

Finally, it should be emphasised that ecological footprint calculators are no be-all, end-all solution to planetary boundary-crossing. On their own, these interventions may deflect environmental responsibility away from corporations, and wrongly place it upon individual consumers [92]. Instead, calculators should be supplementary to legislation and regulation, both of which are necessary to facilitate changes at the industry level and to remove infrastructural and economical barriers to individual behaviour change $[17,31,93]$. Additionally, calculators consider only private-sphere environmental behaviour, meaning public-sphere behaviours (e.g., commitment to environmental organisations or participation in demonstrations) are not considered. Nonetheless, it is worth investigating how ecological footprint calculators could be made more effective, since the small changes in behaviour they encourage could have substantial consequences for the environment if these changes were to be widely adopted.

Supplementary Materials: The following are available online at www.mdpi.com/xxx/s1: Survey Questions (Dutch); Survey Questions (English); Recruitment Details, Data Preparation, and Outliers; Ecological Footprint Calculator Questions (Dutch).

Author Contributions: Conceptualisation, A.K. and W.B..; methodology, A.K. and W.B..; formal analysis, A.K.; investigation, A.K.; writing-original draft preparation, A.K.; writing-review and editing, A.K. and W.B.; supervision, W.B. All authors have read and agreed to the published version of the manuscript.

Institutional Review Board Statement: All participants gave their informed consent for inclusion before they participated in the study. The study was conducted in accordance with the Declaration of Helsinki, and the protocol was approved on April 20, 2020 by the Ethical Review Board of the Human-Technology Interaction group at Eindhoven University of Technology (experiment ID 1097).

Funding: This research received no external funding.

Data Availability Statement: Most of the data presented in this study is openly available in the Open Science Framework at https://doi.org/10.17605/OSF.IO/ZMJ95. Data from 37 out of 448 participants are not included in the public dataset because these participants did not give consent to share their data publicly. Answers to the open question about income were recoded into brackets prior to sharing, as income is considered sensitive data.

Acknowledgments: This research was supported by the Irène Curie Fellowship of Eindhoven University of Technology.

Conflicts of Interest: The authors declare no conflict of interest.

\section{References}

1. Steffen, W.; Crutzen, P.J.; McNeill, J. The Anthropocene: Are humans now overwhelming the great forces of nature? AMBIO A J. Hum. Environ. 2007, 36, 614-621, doi:10.1579/0044-7447(2007)36[614:TAAHNO]2.0.CO;2. 
2. Rockström, J.; Steffen, W.; Noone, K.; Persson, Å.; Chapin, F.S.; Lambin, E.F.; Lenton, T.M.; Scheffer, M.; Folke, C.; Schellnhuber, H.J.; et al. A safe operating space for humanity. Nature 2009, 461, 472-475, doi:10.1038/461472a.

3. Stocker, T.F.; Qin, D.; Plattner, G.K.; Tignor, M.M.B.; Allen, S.K.; Boschung, J.; Nauels, A.; Xia, Y.; Bex, V.; Midgley, P.M. Summary for policymakers. In Climate change 2013: The physical science basis. Contribution of Working Group I to the Fifth Assessment Report of the Intergovernmental Panel on Climate Change; Stocker, T.F., Qin, D., Plattner, G.-K., Tignor, M., Allen, S., Boschung, J., Nauels, A., Xia, Y., Bex, V., Midgley, P., Eds.; Cambridge University Press: Cambridge, UK, and New York, NY, USA, 2014; pp. 3-29.

4. Kang, S.; Eltahir, E.A.B. North China Plain threatened by deadly heatwaves due to climate change and irrigation. Nat. Commun. 2018, 9, doi:10.1038/s41467-018-05252-y.

5. Milly, P.C.D.; Wetherald, R.T.; Dunne, K.A.; Delworth, T.L. Increasing risk of great floods in a changing climate. Nature 2002, 415, 514-517, doi:10.1038/415514a.

6. Ivanova, D.; Stadler, K.; Steen-Olsen, K.; Wood, R.; Vita, G.; Tukker, A.; Hertwich, E.G. Environmental impact assessment of household consumption. J. Ind. Ecol. 2016, 20, 526-536, doi:10.1111/jiec.12371.

7. Salo, M.; Mattinen-Yuryev, M.K.; Nissinen, A. Opportunities and limitations of carbon footprint calculators to steer sustainable household consumption - Analysis of Nordic calculator features. J. Clean. Prod. 2019, 207, 658-666, doi:10.1016/j.jclepro.2018.10.035.

8. West, S.E.; Owen, A.; Axelsson, K.; West, C.D. Evaluating the use of a carbon footprint calculator: Communicating impacts of consumption at household level and exploring mitigation options. J. Ind. Ecol. 2016, 20, 396-409, doi:10.1111/jiec.12372.

9. Lin, D.; Hanscom, L.; Martindill, J.; Borucke, M.; Cohen, L.; Galli, A.; Lazarus, E.; Zokai, G.; Iha, K.; Wackernagel, M. Working Guidebook to the National Footprint and Biocapacity Accounts; Oakland, CA, 2019;

10. Carmi, N.; Arnon, S.; Orion, N. Transforming environmental knowledge into behavior: The mediating role of environmental emotions. J. Environ. Educ. 2015, 46, 183-201, doi:10.1080/00958964.2015.1028517.

11. Díaz-Siefer, P.; Neaman, A.; Salgado, E.; Celis-Diez, J.; Otto, S. Human-environment system knowledge: A correlate of pro-environmental behavior. Sustainability 2015, 7, 15510-15526, doi:10.3390/su71115510.

12. Hsu, J.L.; Lin, T.Y. Carbon reduction knowledge and environmental consciousness in Taiwan. Manag. Environ. Qual. An Int. J. 2015, 26, 37-52, doi:10.1108/MEQ-08-2013-0094.

13. Csutora, M. One more awareness gap? The behaviour-impact gap problem. J. Consum. Policy 2012, 35, 145-163, doi:10.1007/s10603-012-9187-8.

14. Huddart Kennedy, E.; Krahn, H.; Krogman, N.T. Are we counting what counts? A closer look at environmental concern, pro-environmental behaviour, and carbon footprint. Local Environ. 2015, 20, 220-236, doi:10.1080/13549839.2013.837039.

15. Fogg, B.J. Computers as persuasive social actors. In Persuasive technology: Using computers to change what we think and do; Morgan Kaufmann: San Francisco, CA, 2003; pp. 89-120 ISBN 978-1-55860-643-2.

16. Midden, C.J.H.; Ham, J. Persuasive technology to promote environmental behavior. In Environmental psychology: an introduction; Steg, L., Van den Berg, A.E., De Groot, J.I.M., Eds.; Wiley-Blackwell, 2016; pp. 244-254.

17. Büchs, M.; Bahaj, A.B.S.; Blunden, L.; Bourikas, L.; Falkingham, J.; James, P.; Kamanda, M.; Wu, Y. Promoting low carbon behaviours through personalised information? Long-term evaluation of a carbon calculator interview. Energy Policy 2018, 120, 284-293, doi:10.1016/j.enpol.2018.05.030.

18. Gurusinga, N. The effectiveness of using carbon footprint calculator to increase students' awareness and motivation to adopt a low-carbon lifestyle. MSc thesis, University of Melbourne, Melbourne, 2016.

19. Aichholzer, G.; Allhutter, D.; Strauß, S. Using online carbon calculators for participation in local climate initiatives. In Proceedings of the International Conference on Electronic Participation; Spring: Berlin, Heidelberg, 2012; pp. 85-96.

20. Gram-Hanssen, K.; Christensen, T.H. Carbon calculators as a tool for a low-carbon everyday life? Sustain. Sci. Pract. Policy 2012, 8, 19-30, doi:10.1080/15487733.2012.11908093. 
21. Hunter, C.; Carmichael, K.; Pangbourne, K. Household ecological footprinting using a new diary-based data-gathering approach. Local Environ. 2006, 11, 307-327, doi:10.1080/13549830600558804.

22. Collins, A.; Galli, A.; Hipwood, T.; Murthy, A. Living within a One Planet reality: the contribution of personal Footprint calculators. Environ. Res. Lett. 2020, 15, 025008, doi:10.1088/1748-9326/ab5f96.

23. Dreijerink, L.J.M.; Paradies, G.L. How to reduce individual environmental impact? A literature review into the effects and behavioral change potential of carbon footprint calculators; TNO: Petten, 2020;

24. Truelove, H.B. An investigation of the psychology of global warming: Perceptions, predictors of behavior, and the persuasiveness of ecological footprint calculators. PhD thesis, Washington State University, Pullman, WA, 2009.

25. Van Dam, S.S.; Bakker, C.A.; Van Hal, J.D.M. Home energy monitors: impact over the medium-term. Build. Res. Inf. 2010, 38, 458-469, doi:10.1080/09613218.2010.494832.

26. Hargreaves, T.; Nye, M.; Burgess, J. Keeping energy visible? Exploring how householders interact with feedback from smart energy monitors in the longer term. Energy Policy 2013, 52, 126-134, doi:10.1016/j.enpol.2012.03.027. Nye, M.; Smith, G.D.; Hargreaves, T.; Burgess, J. Visible Energy Trial: Report for OFGEM; Norwich, UK, 2010;

28. Sutcliffe, M.; Hooper, P.; Howell, R. Can eco-footprinting analysis be used successfully to encourage more sustainable behaviour at the household level? Sustain. Dev. 2008, 16, 1-16, doi:10.1002/sd.327.

29. Lin, S. Reducing students' carbon footprints using personal carbon footprint management system based on environmental behavioural theory and persuasive technology. Environ. Educ. Res. 2016, 22, 658-682, doi:10.1080/13504622.2015.1018142.

30. Gifford, R.; Nilsson, A. Personal and social factors that influence pro-environmental concern and behaviour: A review. Int. J. Psychol. 2014, 49, 141-157.

31. Kollmuss, A.; Agyeman, J. Mind the Gap: Why do people act environmentally and what are the barriers to pro-environmental behavior? Environ. Educ. Res. 2002, 8, 239-260, doi:10.1080/13504620220145401.

32. Stern, P.C. New environmental theories: Toward a coherent theory of environmentally significant behavior. J. Soc. Issues 2000, 56, 407-424, doi:10.1111/0022-4537.00175.

33. Steg, L.; Perlaviciute, G.; van der Werff, E.; Lurvink, J. The significance of hedonic values for environmentally relevant attitudes, preferences, and actions. Environ. Behav. 2014, 46, 163-192, doi:10.1177/0013916512454730.

34. De Groot, J.I.M.; Steg, L. Value orientations to explain beliefs related to environmental significant behavior. Environ. Behav. 2008, 40, 330-354, doi:10.1177/0013916506297831.

35. Bouman, T.; Verschoor, M.; Albers, C.J.; Böhm, G.; Fisher, S.D.; Poortinga, W.; Whitmarsh, L.; Steg, L. When worry about climate change leads to climate action: How values, worry and personal responsibility relate to various climate actions. Glob. Environ. Chang. 2020, 62, 102061, doi:10.1016/j.gloenvcha.2020.102061.

36. Gatersleben, B.; Murtagh, N.; Abrahamse, W. Values, identity and pro-environmental behaviour. Contemp. Soc. Sci. 2014, 9 , 374-392, doi:10.1080/21582041.2012.682086.

37. Gatersleben, B.; Steg, L.; Vlek, C. Measurement and determinants of environmentally significant behavior. Environ. Behav. 2002, 34, 335-362, doi:10.1177/0013916502034003004.

38. Jones, R. V.; Lomas, K.J. Determinants of high electrical energy demand in UK homes: Socio-economic and dwelling characteristics. Energy Build. 2015, 101, 24-34, doi:10.1016/j.enbuild.2015.04.052.

39. Gatersleben, B. Sustainable household consumption and quality of life: the acceptability of sustainable consumption patterns and consumer policy strategies. Int. J. Environ. Pollut. 2001, 15, 200-216, doi:10.1504/IJEP.2001.000596.

40. Han, L.; Xu, X.; Han, L. Applying quantile regression and Shapley decomposition to analyzing the determinants of household embedded carbon emissions: Evidence from urban China. J. Clean. Prod. 2015, 103, 219-230, doi:10.1016/j.jclepro.2014.08.078.

41. Moser, S.; Kleinhückelkotten, S. Good intents, but low impacts: Diverging importance of motivational and socioeconomic determinants explaining pro-environmental behavior, energy use, and carbon footprint. Environ. Behav. 2018, 50, 626-656, 


\section{doi:10.1177/0013916517710685.}

42. Bruderer Enzler, H.; Diekmann, A. Environmental impact and pro-environmental behavior: Correlations to income and environmental concern; ETH Zurich Sociology Working Papers: Zurich, 2015;

43. Peters, V.; Reusswig, F.; Altenburg, C. European citizens, carbon footprints and their determinants - Lifestyles and urban form. In Mitigating climate change; Khare, A., Beckman, T., Eds.; Springer Environmental Science and Engineering: Berlin, Heidelberg, 2013; pp. 223-245.

44. Poortinga, W.; Steg, L.; Vlek, C. Values, environmental concern, and environmental behavior: A study into household energy use. Environ. Behav. 2004, 36, 70-93, doi:10.1177/0013916503251466.

45. Kaiser, F.G.; Fuhrer, U. Ecological behavior's dependency on different forms of knowledge. Appl. Psychol. 2003, 52, 598-613, doi:10.1111/1464-0597.00153.

46. Frick, J.; Kaiser, F.G.; Wilson, M. Environmental knowledge and conservation behavior: Exploring prevalence and structure in a representative sample. Pers. Individ. Dif. 2004, 37, 1597-1613, doi:10.1016/j.paid.2004.02.015.

47. Levine, D.S.; Strube, M.J. Environmental attitudes, knowledge, intentions and behaviors among college students. J. Soc. Psychol. 2012, 152, 308-326, doi:10.1080/00224545.2011.604363.

48. Coyle, K. Environmental literacy in America: What ten years of NEETF/Roper research and related studies say about environmental literacy in the U.S.; Washington DC, 2005;

49. Fielding, K.S.; Head, B.W. Determinants of young Australians' environmental actions: the role of responsibility attributions, locus of control, knowledge and attitudes. Environ. Educ. Res. 2012, 18, 171-186, doi:10.1080/13504622.2011.592936.

50. Geiger, S.M.; Geiger, M.; Wilhelm, O. Environment-specific vs. general knowledge and their role in pro-environmental behavior. Front. Psychol. 2019, 10, 718, doi:10.3389/fpsyg.2019.00718.

51. Liobikienè, G.; Poškus, M.S. The importance of environmental knowledge for private and public sphere pro-environmental behavior: Modifying the Value-Belief-Norm Theory. Sustainability 2019, 11, 3324, doi:10.3390/su11123324.

52. Hines, J.M.; Hungerford, H.R.; Tomera, A.N. Analysis and synthesis of research on responsible environmental behavior: A meta-analysis. J. Environ. Educ. 1987, 18, 1-8, doi:10.1080/00958964.1987.9943482.

53. Bamberg, S.; Möser, G. Twenty years after Hines, Hungerford, and Tomera: A new meta-analysis of psycho-social determinants of pro-environmental behaviour. J. Environ. Psychol. 2007, 27, 14-25, doi:10.1016/j.jenvp.2006.12.002.

54. Liu, P.; Teng, M.; Han, C. How does environmental knowledge translate into pro-environmental behaviors? The mediating role of environmental attitudes and behavioral intentions. Sci. Total Environ. 2020, 728, 138126, doi:10.1016/j.scitotenv.2020.138126.

55. Paço, A.; Lavrador, T. Environmental knowledge and attitudes and behaviours towards energy consumption. J. Environ. Manage. 2017, 197, 384-392, doi:10.1016/j.jenvman.2017.03.100.

56. Polonsky, M.J.; Vocino, A.; Grau, S.L.; Garma, R.; Ferdous, A.S. The impact of general and carbon-related environmental knowledge on attitudes and behaviour of US consumers. J. Mark. Manag. 2012, 28, 238-263, doi:10.1080/0267257X.2012.659279.

57. Laroche, M.; Tomiuk, M.-A.; Bergeron, J.; Barbaro-Forleo, G. Cultural differences in environmental knowledge, attitudes, and behaviours of Canadian consumers. Can. J. Adm. Sci. 2009, 19, 267-282, doi:10.1111/j.1936-4490.2002.tb00272.x.

58. Caparoso, J.K. V; Aguilar, L.T.M.; Lagura, R.T.; Evangelista, E. V Does climate change education result to less carbon? Norm. Light. 2018, 12, 31-66.

59. Taddicken, M.; Reif, A.; Hoppe, I. What do people know about climate change - and how confident are they? On measurements and analyses of science related knowledge. J. Sci. Commun. 2018, 17, A01, doi:10.22323/2.17030201.

60. Tobler, C.; Visschers, V.H.M.; Siegrist, M. Consumers' knowledge about climate change. Clim. Chang. 2012, 114, 189-209, doi:10.1007/s10584-011-0393-1.

61. Mulrow, J.; Machaj, K.; Deanes, J.; Derrible, S. The state of carbon footprint calculators: An evaluation of calculator design 
and user interaction features. Sustain. Prod. Consum. 2019, 18, 33-40, doi:10.1016/j.spc.2018.12.001.

62. Bouman, T.; Steg, L.; Kiers, H.A.L. Measuring values in environmental research: a test of an Environmental Portrait Value Questionnaire. Front. Psychol. 2018, 9, 564, doi:10.3389/fpsyg.2018.00564.

63. Schwartz, S.H. A proposal for measuring value orientations across nations; 2003;

64. Yan, T.; Curtin, R.; Jans, M. Trends in income nonresponse over two decades. J. Off. Stat. 2010, 26, $145-164$.

65. Karlin, B.; Davis, N.; Sanguinetti, A.; Gamble, K.; Kirkby, D.; Stokols, D. Dimensions of conservation. Environ. Behav. 2014, 46, 423-452, doi:10.1177/0013916512467532.

66. Torgler, B.; Garcia-Valiñas, M.A.; Macintyre, A. Differences in preferences towards the environment: The impact of a gender, age and parental effect; 2008;

67. CBS Onderwijsniveau bevolking 15 tot 75 jaar. Available online: https://longreads.cbs.nl/trends18/maatschappij/cijfers/onderwijs/ (accessed on May 4, 2020).

68. Doornik, J.A.; Hansen, H. An Omnibus Test for Univariate and Multivariate Normality. Oxf. Bull. Econ. Stat. 2008, 70, 927-939, doi:10.1111/j.1468-0084.2008.00537.x.

69. Tolppanen, S.; Kang, J. The effect of values on carbon footprint and attitudes towards pro-environmental behavior. J. Clean. Prod. 2021, 282, 124524, doi:10.1016/j.jclepro.2020.124524.

70. Kok, G.; Gottlieb, N.H.; Peters, G.J.Y.; Mullen, P.D.; Parcel, G.S.; Ruiter, R.A.C.; Fernández, M.E.; Markham, C.; Bartholomew, L.K. A taxonomy of behaviour change methods: an Intervention Mapping approach. Health Psychol. Rev. 2016, 10, 297-312, doi:10.1080/17437199.2015.1077155.

71. Noar, S.M.; Benac, C.N.; Harris, M.S. Does tailoring matter? Meta-analytic review of tailored print health behavior change interventions. Psychol. Bull. 2007, 133, 673-693, doi:10.1037/0033-2909.133.4.673.

72. Masthoff, J.; Grasso, F.; Ham, J. Preface to the special issue on personalization and behavior change. User Model. User-adapt. Interact. 2014, 24, 345-350, doi:10.1007/s11257-014-9151-1.

73. Starke, A.; Willemsen, M.; Snijders, C. Effective user interface designs to increase energy-efficient behavior in a Rasch-based energy recommender system. In Proceedings of the RecSys 2017 - Proceedings of the 11th ACM Conference on Recommender Systems; Association for Computing Machinery, Inc: New York, NY, USA, 2017; pp. 65-73.

74. Bolderdijk, J.W.; Gorsira, M.; Keizer, K.; Steg, L. Values determine the (in)effectiveness of informational interventions in promoting pro-environmental behavior. PLoS One 2013, 8, 83911, doi:10.1371/journal.pone.0083911.

75. Gromet, D.M.; Kunreuther, H.; Larrick, R.P. Political ideology affects energy-efficiency attitudes and choices. Proc. Natl. Acad. Sci. U. S. A. 2013, 110, 9314-9319, doi:10.1073/pnas.1218453110.

76. Kidwell, B.; Farmer, A.; Hardesty, D.M. Getting liberals and conservatives to go green: political ideology and congruent appeals. J. Consum. Res. 2013, 40, 350-367, doi:10.1086/670610.

Feinberg, M.; Willer, R. The moral roots of environmental attitudes. Psychol. Sci. 2013, 24, 56-62, doi:10.1177/0956797612449177.

78. Wolsko, C.; Ariceaga, H.; Seiden, J. Red, white, and blue enough to be green: Effects of moral framing on climate change attitudes and conservation behaviors. J. Exp. Soc. Psychol. 2016, 65, 7-19, doi:10.1016/j.jesp.2016.02.005.

79. $\mathrm{Xu}, \mathrm{X}$; Arpan, L.M.; Chen, C.F. The moderating role of individual differences in responses to benefit and temporal framing of messages promoting residential energy saving. J. Environ. Psychol. 2015, 44, 95-108, doi:10.1016/j.jenvp.2015.09.004.

80. Nilsson, A.; Hansla, A.; Heiling, J.M.; Bergstad, C.J.; Martinsson, J. Public acceptability towards environmental policy measures: Value-matching appeals. Environ. Sci. Policy 2016, 61, 176-184, doi:10.1016/j.envsci.2016.04.013.

81. Van den Broek, K.; Bolderdijk, J.W.; Steg, L. Individual differences in values determine the relative persuasiveness of biospheric, economic and combined appeals. J. Environ. Psychol. 2017, 53, 145-156, doi:10.1016/j.jenvp.2017.07.009. Hansla, A. Value orientation and framing as determinants of stated willingness to pay for eco-labeled electricity. Energy Effic. 2011, 4, 185-192, doi:10.1007/s12053-010-9096-0. 
83. Arpan, L.M.; Xu, X.; Raney, A.A.; Chen, C.F.; Wang, Z. Politics, values, and morals: Assessing consumer responses to the framing of residential renewable energy in the United States. Energy Res. Soc. Sci. 2018, 46, 321-331, doi:10.1016/j.erss.2018.08.007.

84. Knowles, B.; Blair, L.; Walker, S.; Coulton, P.; Thomas, L.; Mullagh, L. Patterns of persuasion for sustainability. In Proceedings of the Proceedings of the Conference on Designing Interactive Systems: Processes, Practices, Methods, and Techniques (DIS); Association for Computing Machinery: New York, New York, USA, 2014; pp. 1035-1044.

85. Kim, B.; Neff, R. Measurement and communication of greenhouse gas emissions from U.S. food consumption via carbon calculators. Ecol. Econ. 2009, 69, 186-196, doi:10.1016/j.ecolecon.2009.08.017.

86. Coulter, A.; Clegg, S.; Lyons, G.; Chatterton, T.; Musselwhite, C. Exploring public attitudes to personal carbon dioxide emission information; London, 2007;

87. Chatterton, T.J.; Coulter, A.; Musselwhite, C.; Lyons, G.; Clegg, S. Understanding how transport choices are affected by the environment and health: Views expressed in a study on the use of carbon calculators. Public Health 2009, 123, e45-e49, doi:10.1016/j.puhe.2008.10.022.

88. Fischer, C. Feedback on household electricity consumption: A tool for saving energy? Energy Effic. 2008, 1, 79-104, doi:10.1007/s12053-008-9009-7.

89. Rettie, R.; Burchell, K.; Harries, T. Energy consumption feedback: Engagement by design. In Proceedings of the Design, User Experience, and Usability. User Experience Design for Everyday Life Applications and Services. DUXU 2014; Springer, Cham, 2014; Vol. 8519 LNCS, pp. 594-604.

90. Bottrill, C. Internet-based carbon tools for behaviour change; Oxford, UK, 2007;

91. Padgett, J.P.; Steinemann, A.C.; Clarke, J.H.; Vandenbergh, M.P. A comparison of carbon calculators. Environ. Impact Assess. Rev. 2008, 28, 106-115, doi:10.1016/j.eiar.2007.08.001.

92. Doyle, J. Where has all the oil gone? BP branding and the discursive elimination of climate change risk. In Culture, Environment and Eco-Politics; Heffernan, N., Wragg, D., Eds.; Cambridge Scholars Press: Newcastle Upon Tyne, UK, 2011; pp. 200-225.

93. Lorenzoni, I.; Nicholson-Cole, S.; Whitmarsh, L. Barriers perceived to engaging with climate change among the UK public and their policy implications. Glob. Environ. Chang. 2007, 17, 445-459, doi:10.1016/j.gloenvcha.2007.01.004. 